\title{
Two New Labdane Diterpene Glycoside from Flowers of Bacchris Medulosa DC
}

\section{D.A. Cifuente, C.E. Tonn and O.S. Giordano}

INTEQUI-CONICET-Facultad de Química, Bioquímica y Farmacia. Chacabuco y Pedernera-5700San Luis, Argentina

E-mail: cifuente@unsl.edu.ar

\begin{abstract}
Two new labdane-type diterpene glycoside, were isolated from the flowers of Baccharis medulosa DC (Asteraceae). Structures of these compounds were established by application of various spectroscopic techniques.
\end{abstract}

\section{Introduction}

In continuation of our studies on diterpenic compounds of Baccharis [1] genus (Compositae, tribe Astereae), we have investigated B. medulosa DC. In the present work, we described the isolation, characterization and structural determination of two new labdane-type diterpene glycoside [2] (1 and 2).

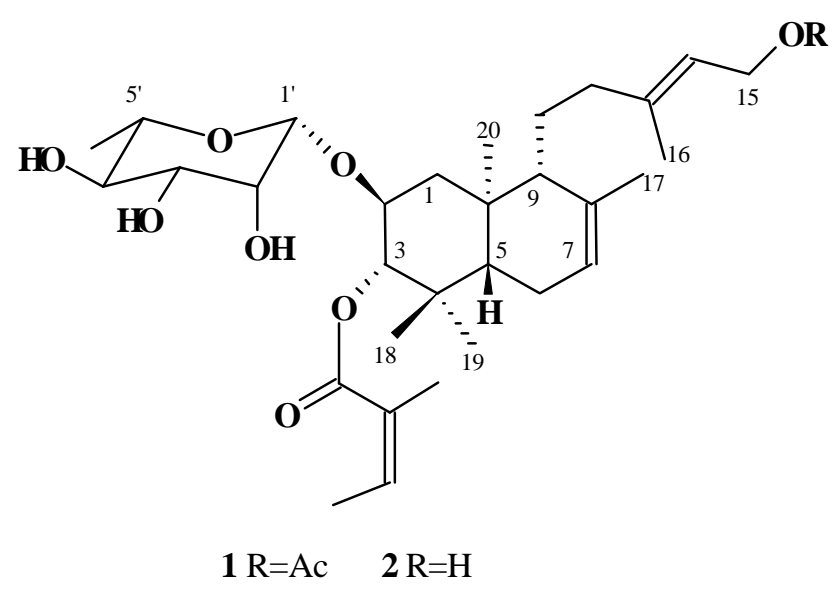

\section{Experimental}

Plant material. B. medulosa DC, was collected in Juana Koslay, San Luis, Province of Argentina in March 1998. Voucher No 986 . UNSL.

Extraction and isolation. Fresh flowers $(2 \mathrm{Kg})$ of $B$. medulosa were extracted with $\mathrm{Me}_{2} \mathrm{CO}$ at room temp. The $\mathrm{Me}_{2} \mathrm{CO}$ extract was dissolved in $\mathrm{MeOH}: \mathrm{H}_{2} \mathrm{O}$ (8:2) and the soln was successively partitioned against, $n$-hexane, $\mathrm{CCl}_{4}, \mathrm{CHCl}_{3}$ and EtOAc. The $\mathrm{CCl}_{4}$ and $\mathrm{CHCl}_{3}$ extracts were subjected to several 
several C.C. purifications on Si gel eluted with $n$-hexane, $n$-hexane:EtOAc increasing polarity mixtures and EtOAc - MeOH (97:3). The more polar fractions were purified by Sephadex LH-20 and RP-18 C.C., eluted with $\mathrm{MeOH}-\mathrm{H}_{2} \mathrm{O}$ (90:10 and 85:15) to yield 1 (300 mg) and 2 (250 mg). The sugar residues as TMS derivative were identified by GC analysis using suitable sugar standard after acid hydrolysis [3] of the natural products.

\section{Results and Discussion}

The NMR spectroscopical data for these compounds suggested nearly structural relationship according with a labdane-type glycoside framework. The ${ }^{13} \mathrm{C}$ NMR spectrum of $\mathbf{1}$, gave 33 carbon signals, which were coupled with DEPT experiments. Signals attributable to seven quaternary carbons, nine methyl carbons, five methylenes and twelve methine groups, were observed. The ${ }^{1} \mathrm{H}$ NMR spectral data showed the presence of three tertiary methyl groups at $\delta 0.85 \mathrm{~s}, 0.97 \mathrm{~s}$ and $0.82 \mathrm{~s}$ attributable each one to $\mathrm{H}-18, \mathrm{H}-19$, and $\mathrm{H}-20$ on the decaline moiety. Two overlapping olefinic protons at $\delta 5.35$ brt and $\delta 5.40$ brs, both allylically coupled with methyl groups ( $\delta 1.69$ brs and 1.71 brs) were assigned to $\mathrm{H}-7$ and $\mathrm{H}-14$, respectively. From the COSY spectrum cross peaks observed between signals at $\delta$ $3.87(\mathrm{ddd}, \mathrm{J}=12.0,11.0,3.8 \mathrm{~Hz}$ ) and $\delta 4.72(\mathrm{~d}, \mathrm{~J}=10.5 \mathrm{~Hz})$, were associated with $\mathrm{H}-2$ and $\mathrm{H}-3$, both on oxygenated carbons. Additional signals at $\delta 2.08 \mathrm{~s}$ and $\delta 4.59$ (brd, $\mathrm{J}=7.3 \mathrm{~Hz}$ ) indicated the presence of an acetate group on the allylic hydroxymethyl function at C-15. On the other hand, signals at $\delta_{\mathrm{C}} 103$, $\delta_{\mathrm{H}} 4.19(\mathrm{~d}, \mathrm{~J}=7.1 \mathrm{~Hz})$ were agreeable with an anomeric proton; whose coupling constant indicated that the glycosidic linkage had $\beta$-configuration. One signal at $\delta_{\mathrm{H}} 1.25 \mathrm{~d}(\mathrm{~J}=7.0 \mathrm{~Hz})$ suggested that the sugar moiety was a methylpentose (L-rhamnose). Typical signals at $\delta_{\mathrm{H}} 6.15 \mathrm{qq}, 1.99 \mathrm{dq}, 1.92 \mathrm{dq}$ were in agreement with the presence of an angelate group. The site of attachment of the saccharide residue as well as the position of the angelate group were established on the basis of long range HMBC experiments.

Except for the acetoxymethylene group signals, NMR spectral data of compound 2 were closely related with the spectral data observed for compound 1 . In place of the signals at $\delta_{\mathrm{H}} 4.59$, one signal at $\delta_{\mathrm{H}} 4.12$ brd for an hydroxymethyl group, was observed.

Acknowledgements: Financial support of CONICET and UNSL. We thank Ing. L.A. del Vitto for plant identification, Professors E. Manta, P.C. Rossomando and E. Garcia for NMR measurements, Professor O. Varela for sugar standards.

\section{References and Notes}

1. Ceñal, J.P.; Giordano, O.S.; Rossomando, P.C.; Tonn, C.E. J. Nat. Prod. 1997, 60 (5), 490.

2. Zdero, C.; Bholmann, F.; King, R.M.; Robinson, H. Phytochemistry 1986, 25 (12), 2841.

3. Jahan, N.; Ahmed, W.; Malik, A. J. Nat. Prod. 1995, 58 (8), 1244. 